\title{
Effect of protective lung ventilation strategy combined with lung recruitment maneuver in patients with acute respiratory distress syndrome (ARDS)
}

\author{
Sheng $\mathrm{Yu}^{1 \#}$, Tian-Xiao $\mathrm{Hu}^{2 \#}$, Jun Jin ${ }^{3}$, Sheng Zhang ${ }^{4 \bowtie}$ \\ ${ }^{1}$ Department of Intensive Care Unit, Changshu Second People's Hospital in Jiangsu Province, Changshu 215500, China \\ ${ }^{2}$ Endocrinology Department, the 117th Hospital of PLA, Hangzhou 310013, China \\ ${ }^{3}$ Department of Intensive Care Unit, the First Affiliated Hospital of Suzhou University, Suzhou 215006, China \\ ${ }^{4}$ Department of Emergency and Intensive Care Unit, Changzheng Hospital Affiliated to the Second Military Medical University, Shanghai 200003, \\ China
}

${ }^{4}$ Department of Emergency and Intensive Care Unit, Changzheng Hospital Affiliated to the Second Military Medical University, Shanghai 200003, China

\section{ARTICLE INFO}

\section{Article history:}

Received April 2017

Received in revised form 15 May 2017

Accepted 25 May 2017

Available online 1 July 2017

\section{Keywords:}

Acute respiratory distress syndrome

Lung recruitment maneuver

Mechanical ventilation

Positive end expiratory pressure

\begin{abstract}
Objective: To evaluate the efficacy and safety of protective lung ventilation strategy combined with lung recruitment maneuver (RM) in the treatment patients with acute respiratory distress syndrome (ARDS). Methods: Totally 74 patients with ARDS admitted to the Department of Intensive Care Unit, Changshu Second People's Hospital in Jiangsu Province between September 2010 and June 2013 were selected and randomly divided into lung recruitment group and non-recruitment group, and the initial ventilation mode for both groups was synchronized intermittent mandatory ventilation (SIMV). Lung recruitment was performed in condition of SIMV mode (pressure control and pressure support). Positive end expiratory pressure (PEEP) was increased by $5 \mathrm{~cm} \mathrm{H} \mathrm{H}_{2} \mathrm{O}$ every time and maintained for 40-50 s before entering the next increasing circle, and the peak airway pressure was always kept below $45 \mathrm{~cm}$ $\mathrm{H}_{2} \mathrm{O}$. After PEEP reached the maximum value, it was gradually reduced by $5 \mathrm{~cm} \mathrm{H}_{2} \mathrm{O}$ every time and finally maintained at $15 \mathrm{~cm} \mathrm{H} \mathrm{H}_{2} \mathrm{O}$ for $10 \mathrm{~min}$. Results: A total of 74 patients with mean age of $(49.0 \pm 18.6)$ years old were enrolled, 36 patients were enrolled in lung recruitment maneuver (RM) group and 38 patients were enrolled into non-lung recruitment maneuver (nonRM) group. 44 were male and accounted for $59.5 \%$ of all the patients. For the indicators such as PEEP, pressure support (PS), plateau airway pressure $\left(\mathrm{P}_{\text {plat }}\right)$, peak airway pressure $\left(\mathrm{P}_{\text {peak }}\right)$, vital capacity (VC) and fraction of inspired oxygen $\left(\mathrm{FiO}_{2}\right)$, no statistical differences in the indicators were found between the RM group and non-RM group on D1, D3 and D7 $(P>0.05)$, except that only $\mathrm{FiO}_{2}$ of RM group on D7 was significantly lower than that of non-RM group $[(47.2 \pm 10.0)$ vs. $(52.2 \pm 10.5), P<0.05]$. For the indicators of blood gas analysis, including $\mathrm{pH}$, arterial partial pressure of oxygen $\left(\mathrm{PaO}_{2}\right)$, arterial partial pressure of carbon dioxide $\left(\mathrm{PaCO}_{2}\right)$ and oxygenation index $\left(\mathrm{PaO}_{2} / \mathrm{FiO}_{2}\right), \mathrm{PaO}_{2}$ and $\mathrm{PaO}_{2} / \mathrm{FiO}_{2}$ of $\mathrm{RM}$ group were significantly higher than those of non-RM group on D7, and the values were $[(90.2 \pm 16.1) \mathrm{mmHg}$ vs. $(76.4 \pm 11.3) \mathrm{mmHg}$, $P<0.05]$ and $[(196.5 \pm 40.7) \mathrm{mmHg}$ vs. $(151.7 \pm 37.3) \mathrm{mmHg}, P<0.05]$ respectively. There was no statistical difference in heart rate (HR), cardiac index (CI), central venous pressure (CVP) or mean arterial pressure (MAP) between RM group and non-RM group on D1, D3 and D7 $(P>0.05)$. 28day mortality, ICU mortality and in-hospital mortality were $25 \%$ vs. $28.9 \%, 25 \%$ vs. $26.3 \%$ and $36.1 \%$ vs. $39.5 \%$ respectively between RM group and non-RM group (all $P>0.05$ ). Conclusion: Protective lung ventilation strategy combined with lung recruitment maneuver can improve the indicators such as $\mathrm{PaO}_{2}, \mathrm{FiO}_{2}$ and $\mathrm{PaO}_{2} / \mathrm{FiO}_{2}$ on $\mathrm{D} 7$, but failed to improve the final outcomes such as 28-day mortality, ICU mortality and in-hospital mortality.
\end{abstract}

\section{Introduction}

Acute respiratory distress syndrome (ARDS) is one of the

\#These authors contributed equally to this work.

* Corresponding author: Sheng Zhang, Department of Emergency and Intensive Care Unit, Changzheng Hospital Affiliated to the Second Military Medical University, Shanghai 200003, China.

Tel: $13701899336 ; 15618504630$

Email: zhangsheng870801@ hotmail.com

Fund Project: Effect and Mechanism of Nrf2/ARE Pathway in Hydrogen Treatment of Seawater Drowning-induced Acute Lung Injury (No: 2016QN19). common critical diseases in the emergency department and ICU, and mechanical ventilation is an important therapy for respiratory support in patients with ARDS [1-3]. In recent years, researches have shown that small tidal volume ventilation $(6$ vs. $12 \mathrm{~mL} / \mathrm{Kg}$ ) of protective lung ventilation strategy can significantly increase the survival rate in patients with ARDS, because this strategy can reduce the shearing injury caused by persistent alveolar opening and closing [4,5]. However, small tidal volume ventilation can also 
cause some unexpected consequences, and the most severe adverse consequence is the alveolar collapse and atelectasis caused by insufficient ventilation [6,7]. Animal experiments has shown that lung recruitment maneuver (RM) can reduce the alveolar collapse caused by small tidal volume ventilation strategy, and improve the oxygenation and respiratory parameters [8]. However, it remains controversial whether RM can improve clinical outcomes in patients with ARDS $[9,10]$. Therefore, we sought to explore whether protective lung ventilation strategy combined with lung recruitment maneuver technique (PEEP increment method) can improve the outcomes of respiratory parameters, blood gas analysis indices, hemodynamic indices, and clinical prognosis in patients with ARDS.

\section{Materials and methods}

\subsection{Study population}

Patients with ARDS admitted to the Department of Intensive Care Unit, Changshu Second People's Hospital in Jiangsu Province between September 2010 and June 2013 were considered potentially eligible. The research was approved by the ethics committee of Changshu Second People's Hospital, and in accordance with the ethics standard of clinical research. All patients or their clients signed written informed consent.

\subsection{Inclusion criteria}

Inclusion criteria was according to the ARDS Berlin standard [1]: patients with factors for ARDS; acute onset, high respiratory frequency and (or) respiratory distress; $\mathrm{X}$ ray showes bilateral infiltrates; cardiac pulmonary edema was eliminated; hypoxemia during mechanical ventilation $\left(\mathrm{PaO}_{2} / \mathrm{FiO}_{2} \leq 300 \mathrm{mmHg}\right)$.

\subsection{Exclusion criteria}

Less than 18 years old; pregnant; the expected hospital stay less than $48 \mathrm{~h}$; with end-stage chronic disease or malignant disease; with intracranial hypertension or neuromuscular disorders; patients with lobectomy; patients without autonomous respiration.

\subsection{Grouping scheme}

A stratified randomized controlled method was used. The enrolled patients were first classified according to the pathogenies of ARDS, and then each type of the patients was randomly assigned to the RM or non-RM group. Random assignment was achieved by computer-generated random number, and sealed envelope was used for allocation concealment.

\subsection{Mechanical ventilation}

Initial ventilation mode was synchronized intermittent mandatory ventilation (SIMV), and the capacity control + pressure support or pressure control + pressure support scheme were prescribed according to patients' conditions. Parameter settings: suitable positive end-expiratory pressure (PEEP) levels were selected, namely the minimum PEEP level to maintain the target oxygenation with the fraction of inspired oxygen $\left(\mathrm{FiO}_{2}\right)$ less than $60 \%$, restricted platform pressure less than $30 \mathrm{~cm} \mathrm{H}_{2} \mathrm{O}$ and tidal volume $6-7 \mathrm{~mL} / \mathrm{kg}[11,12]$; the target parameters: blood gas analysis pH 7.30-7.45, $\mathrm{PaO}_{2} 60-80 \mathrm{mmHg}$ or $\mathrm{SaO}_{2} 90 \%-95 \%, \mathrm{PaCO}_{2}$ $35-55 \mathrm{mmHg}[11,12]$

\subsection{Lung RM process}

Patients were fully sedated (Ramsay score 4-5 grade) before initiation of lung recruitment. Patients received pure oxygen inspiration for $5 \mathrm{~min}$ before lung RM to ensure adequate oxygenation. For RM, ventilators were set as SIMV mode (pressure control + pressure support), and PEEP increment method was applied. PEEP was increased by $5 \mathrm{~cm} \mathrm{H}_{2} \mathrm{O}$ every time from baseline and maintained for 40-50 s before entering into the next PEEP increasing circle. During PEEP incremental process, in order to control the peak airway pressure always below $45 \mathrm{~cm} \mathrm{H}_{2} \mathrm{O}$, when the $\mathrm{P}_{\text {peak }}$ was equal to $45 \mathrm{~cm} \mathrm{H}_{2} \mathrm{O}$, PS was decreased by $5 \mathrm{~cm}$ $\mathrm{H}_{2} \mathrm{O}$ as PEEP increased. After PEEP reached the peak value, it was then reduced by $5 \mathrm{~cm} \mathrm{H}_{2} \mathrm{O}$ every time, and maintained at $15 \mathrm{~cm}$ $\mathrm{H}_{2} \mathrm{O}$ for 10 min. Finally, PEEP and other respiratory parameters were set to the initial levels before lung recruitment. Lung RM flow chart is shown in Figure 1, and each RM lasted for about 17 min and repeated every $8 \mathrm{~h}$ [13].

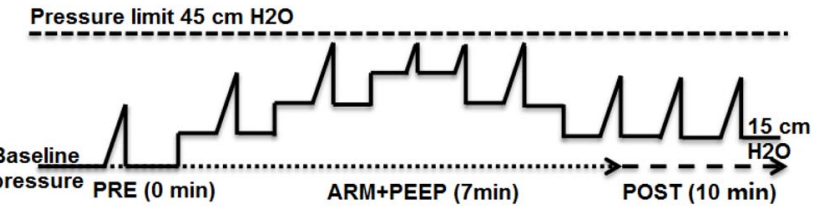

Figure 1. Lung recruitment flow chart.

\subsection{Observations}

The general information, respirator conditions and ARDS causes of the enrolled patients; dynamic changes of respirator parameters such as PEEP, pressure support (PS), plateau airway pressure $\left(\mathrm{P}_{\text {plat }}\right)$, peak airway pressure $\left(\mathrm{P}_{\text {peak }}\right)$, vital capacity $(\mathrm{VC})$ 
and fraction of inspired oxygen $\left(\mathrm{FiO}_{2}\right)$ of $\mathrm{RM}$ group and non-RM group on D1, D3 and D7; blood gas analysis results such as $\mathrm{pH}$, arterial partial pressure of oxygen $\left(\mathrm{PaO}_{2}\right)$, arterial partial pressure of carbon dioxide $\left(\mathrm{PaCO}_{2}\right)$ and oxygenation index $\left(\mathrm{PaO}_{2} / \mathrm{FiO}_{2}\right)$ of RM group and non-RM group on D1, D3 and D7; dynamic change of hemodynamic parameters such as heart rate (HR), cardiac index (CI), central venous pressure (CVP) or mean arterial pressure (MAP) of RM group and non-RM group on D1, D3 and D7; prognostic indicators such as 28-day mortality, ICU mortality, inhospital mortality and incidence of complications.

\subsection{Statistical analysis}

Normally distributed data were expressed as mean (standard deviation), and compared with independent $t$-test; non-normally distributed data were expressed as median (interquartile range), and compared with Wilcoxon-Mann-Whitney test; enumeration data were expressed as number (percentage), and compared by Chi-square test or the Fisher's exact test. Survival curves were built by Kaplan-Meier method, and compared by the Log-rank test. All statistical analysis was performed by SPSS 20.0. $P<0.05$ indicated that the difference was statistically significant.

\section{Results}

\subsection{Study population}

Clinical general data of two groups of patients are shown in Table 1. A total of 74 patients with ARDS were enrolled (36 cases in RM group and 38 cases in non-RM group). 44 patients were male and accounted for $59.5 \%$ of the total amount. The average age was $(49.0 \pm 18.6)$ years old. The common causes of ARDS were lung infections (20 cases), sepsis or septic shock (13 cases), drowning and aspiration ( 9 cases), acute pancreatitis ( 9 cases), pulmonary contusion ( 8 cases), etc in turn. RM group and non-RM group were not statistically different in age, gender, APACHEII score and ARDS causes on admission ( $P>0.05)$, and the clinical data of two groups of patients were comparable.
Table 1

Clinical characteristics of RM group and non-RM group on admission.

\begin{tabular}{lccc}
\hline Clinical characteristics & RM group & $\begin{array}{c}\text { Non-RM } \\
\text { group }\end{array}$ & $P$ \\
\hline Number of people & 36 & 38 & 0.879 \\
Age & $46.9 \pm 15.0$ & $51.1 \pm 21.5$ & 0.394 \\
Male $(n, \%)$ & $21(58.3 \%)$ & $23(60.5 \%)$ & 0.848 \\
Mechanical ventilation time before & & & \\
inclusion & $1(1-3)$ & $1(1-3)$ & 0.757 \\
APACHEII score & $16.6 \pm 5.0$ & $17.6 \pm 4.8$ & 0.809 \\
Number of extra-pulmonary organ & & & \\
failure & $2.1 \pm 1.3$ & $2.0 \pm 1.2$ & 0.732 \\
Oxygenation index & $173.5 \pm 41.2$ & $172.9 \pm 39.0$ & 0.949 \\
Main causes of acute lung injury & & & \\
Lung infections & 9 & 11 & 0.702 \\
Sepsis or septic shock & 7 & 6 & 0.680 \\
Drowning and aspiration & 5 & 4 & 0.658 \\
Acute pancreatitis & 4 & 5 & 0.788 \\
Pulmonary contusion & 4 & 4 & 0.936 \\
Burn & 3 & 2 & 0.599 \\
Acute pulmonary embolism & 1 & 1 & 0.969 \\
Poisoning & 1 & 2 & 0.587 \\
Others & 2 & 3 & 0.689 \\
\hline
\end{tabular}

3.2. Respirator parameters of RM group and non-RM group on D1, D3 and D7

Respirator parameters of two groups of patients on D1, D3 and $\mathrm{D} 7$ are shown in Table 2. For the indicators such as PEEP, PS, $\mathrm{P}_{\text {plat}}$, $\mathrm{P}_{\text {peak }}$, vital capacity $(\mathrm{VC})$ and fraction of inspired oxygen $\left(\mathrm{FiO}_{2}\right)$ in RM group and non-RM group, no statistical differences in the indicators were found between the RM group and non-RM group on D1, D3 and D7 ( $P>0.05)$, except that only $\mathrm{FiO}_{2}$ of $\mathrm{RM}$ group on D7 was significantly lower than that of non-RM group [(47.2 \pm 10.0$)$ vs. $(52.2 \pm 10.5), P<0.05]$.

\subsection{Blood gas analysis results of $R M$ group and non-RM group on D1, D3 and D7}

Blood gas analysis results of two groups of patients on D1, D3 and D7 are shown in Table 3. For all the gas analysis results $[\mathrm{pH}$, arterial partial pressure of oxygen $\left(\mathrm{PaO}_{2}\right)$, arterial partial pressure of carbon dioxide $\left(\mathrm{PaCO}_{2}\right)$ and $\mathrm{PaO}_{2} / \mathrm{FiO}_{2}$ ], only $\mathrm{PaO}_{2}$ and $\mathrm{PaO}_{2} /$ $\mathrm{FiO}_{2}$ of RM group were significantly higher than those of non-RM

Table 2

Comparison of respirator parameters between RM group and non-RM group on D1, D3 and D7.

\begin{tabular}{llccccc}
\hline Time & Group & PEEP $\left(\mathrm{cm} \mathrm{H}_{2} \mathrm{O}\right)$ & PS $\left(\mathrm{cm} \mathrm{H}_{2} \mathrm{O}\right)$ & $\begin{array}{c}\text { Plateau airway } \\
\text { pressure }\left(\mathrm{cm} \mathrm{H}_{2} \mathrm{O}\right)\end{array}$ & $\begin{array}{c}\text { Peak airway pressure } \\
\left(\mathrm{cm} \mathrm{H}_{2} \mathrm{O}\right)\end{array}$ & $\begin{array}{c}\text { Vital capacity } \\
(\mathrm{mL} / \mathrm{kg})\end{array}$ \\
\hline D1 & RM group & $8.3 \pm 2.4$ & $15.9 \pm 4.1$ & $24.2 \pm 5.9$ & $33.9 \pm 4.8$ & $6.6 \pm 1.1$ \\
& Non-RM group & $8.2 \pm 2.3$ & $16.6 \pm 3.8$ & $24.8 \pm 5.6$ & $34.8 \pm 5.6$ & $67.9(11.6)$ \\
D3 & RM group & $7.8 \pm 2.2$ & $15.0 \pm 3.7$ & $22.8 \pm 5.1$ & $32.7 \pm 4.6$ & $6.5 \pm 0.9$ \\
& Non-RM group & $7.6 \pm 1.7$ & $15.5 \pm 3.4$ & $23.1 \pm 4.7$ & $33.2 \pm 5.9$ & $6.4 \pm 1.0$ \\
D7 & RM group & $7.4 \pm 1.6$ & $14.2 \pm 3.3$ & $21.6 \pm 4.3$ & $31.1 \pm 5.0$ & $6.4 \pm 0.9$ \\
& Non-RM group & $7.1 \pm 1.8$ & $14.8 \pm 3.5$ & $21.9 \pm 5.0$ & $32.2 \pm 6.2$ & $6.2 \pm 1.0$ \\
\hline
\end{tabular}

\footnotetext{
" comparison between RM group and non-RM group, $P<0.05$.
} 
group on $\mathrm{D} 7(P<0.05)$.

\subsection{Hemodynamic parameters of RM group and non-RM group on D1, D3 and D7}

Hemodynamic parameters of two groups of patients on D1, D3 and D7 are shown in Table 4. There was no statistical difference in HR, CI, CVP or MAP between RM group and non-RM group on D1, D3 and D7 $(P>0.05)$.

\subsection{Prognosis and complications of patients in RM group and non-RM group}

Prognosis and complications of patients in the two groups are shown in Table 5. 28-day mortality of RM group and non-RM group were $25.0 \%$ and $28.9 \%(P>0.05)$ respectively, and the survival curve (Figure 2) was not statistically different between two groups of patients $(P>0.05)$. Furthermore, ICU mortality $(25.0 \%$ vs. $26.3 \%)$ and in-hospital mortality (36.1\% vs. $39.5 \%)$ were not statistically different between RM group and non-RM group
$(P>0.05)$. Duration of mechanical ventilation, length of ICU stay and length of in-hospital stay for RM group and non-RM group were $10(6-18.75)$ vs. $14.5(7-23.25), 10(9.25-25.25)$ vs. $16.5(11-26.25)$ and $16(12-28.5)$ vs. 26(16-32.5) respectively and not statistically different $(P>0.05)$. The incidence of common ARDS complications, including refractory hypoxemia $(11.1 \%$ vs. $10.5 \%)$, refractory acidosis (13.9\% vs. $10.5 \%$ ) and barotraumas or pneumothorax $(11.1 \%$ vs. $13.2 \%)$ were not statistically different between RM group and non-RM group $(P>0.05)$.

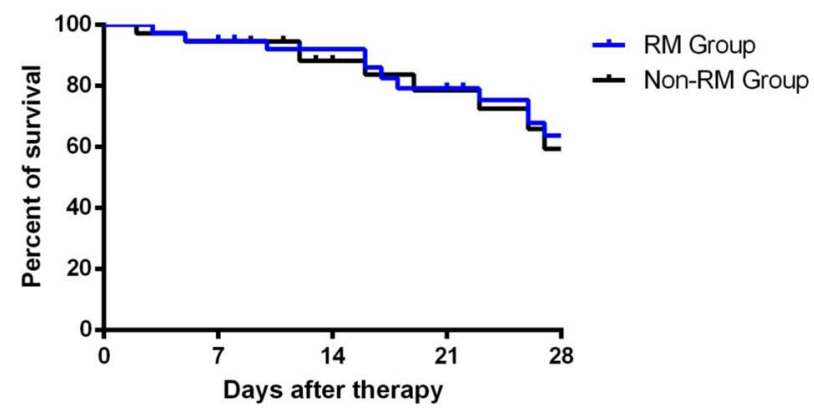

Figure 2. 28 d survival curve of RM group and non-RM group.

Table 3

Comparison of blood gas analysis results between RM group and non-RM group on D1, D3 and D7.

\begin{tabular}{llcccc}
\hline Time & Group & $\mathrm{pH}$ & $\mathrm{PaO}_{2}(\mathrm{mmHg})$ & $\mathrm{PaCO}_{2}(\mathrm{mmHg})$ & $\mathrm{PaO}_{2} / \mathrm{FiO} O_{2}(\mathrm{mmHg})$ \\
\hline D1 & RM group & $7.38 \pm 0.07$ & $85.1 \pm 17.5$ & $41.9 \pm 6.1$ & $129.5 \pm 37.3$ \\
& Non-RM group & $7.38 \pm 0.07$ & $79.1 \pm 12.5$ & $43.5 \pm 6.7$ & $131.9 \pm 37.4$ \\
D3 & RM group & $7.39 \pm 0.04$ & $81.9 \pm 15.0$ & $43.1 \pm 4.0$ & $146.9 \pm 37.7$ \\
& Non-RM group & $7.40 \pm 0.04$ & $76.0 \pm 10.9$ & $41.9 \pm 4.8$ & $137.4 \pm 36.4$ \\
D7 & RM group & $7.39 \pm 0.03$ & $90.2 \pm 16.1$ & $41.9 \pm 4.2$ & $196.5 \pm 40.7$ \\
& Non-RM group & $7.41 \pm 0.03$ & $76.4 \pm 11.3^{\#}$ & $42.8 \pm 6.2$ & $151.7 \pm 37.3^{\#}$ \\
\hline
\end{tabular}

\# comparison between RM group and non-RM group, $P<0.05$.

Table 4

Comparison of hemodynamic parameters between RM group and non-RM group on D1, D3 and D7.

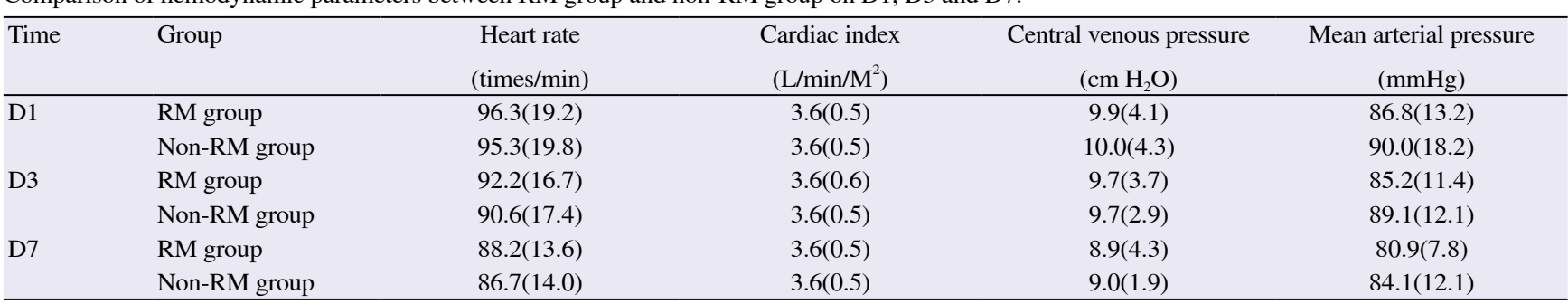

Table 5

Comparison of clinical results between RM group and non-RM group.

\begin{tabular}{|c|c|c|c|}
\hline Clinical characteristics & RM group & Non-RM group & $P$ value \\
\hline 28d mortality $(n, \%)$ & $9(25.0 \%)$ & $11(28.9 \%)$ & 0.702 \\
\hline ICU mortality $(n, \%)$ & $9(25.0 \%)$ & $10(26.3 \%)$ & 0.897 \\
\hline In-hospital mortality $(n, \%)$ & $13(36.1 \%)$ & $15(39.5 \%)$ & 0.766 \\
\hline Duration of mechanical ventilation (days) & $10(6-18.75)$ & $14.5(7-23.25)$ & 0.338 \\
\hline Length of ICU stay (d) & $10(9.25-25.25)$ & $16.5(11-26.25)$ & 0.433 \\
\hline Length of in-hospital stay (d) & $16(12-28.5)$ & $26(16-32.5)$ & 0.119 \\
\hline Refractory hypoxemia incidence $(n, \%)$ & $4(11.1 \%)$ & $4(10.5 \%)$ & 0.936 \\
\hline Refractory acidosis $(n, \%)$ & $5(13.9 \%)$ & $4(10.5 \%)$ & 0.658 \\
\hline Barotraumas or pneumothorax $(n, \%)$ & $4(11.1 \%)$ & $5(13.2 \%)$ & 0.788 \\
\hline
\end{tabular}




\section{Discussion}

In this study, we found that protective lung ventilation strategy combined with lung RM (compared with no implementation of lung RM), can significantly improve patients' oxygenation index on D7, but failed to improve the 28-day mortality, length of hospital stay, incidence of complications and other prognostic indicators.

One of the important pathophysiological characteristics of ARDS is the massive collapse of alveolar, which results in less effective ventilatory volume $[1,14]$. The protective lung ventilation strategy of small tidal volume ventilation can reduce platform pressure and decrease the ventilator-associated lung injury and ARDS mortality, but it goes against the re-expansion of collapsed alveoli in patients with ARDS. Therefore, application of a certain maneuver for lung RM may promote the recruitment of collapsed alveoli, improve oxygenation, reduce intrapulmonary shunt, and even reduce mortality [14-19]. There are many common clinical types of lung RMs, including sustained inflation, sighing respiration, high-frequency oscillatory ventilation, PEEP incremental method, etc., the principles are not the same, but the ultimate goal is re-expansion of collapsed alveoli [20],

It has been more than 20 years since Lanchman first proposed the lung RM concept and applied it in clinical practice in 1992 [21]. During two decades, the lung RMs emerge in endlessly, but it is still inconclusive in both animal experiments and clinical research whether lung recruitment can improve the prognosis of patients with ARDS. In this study, lung recruitment failed to improve the patient's primary and secondary outcomes. The conclusions of previous clinical studies are also different, some studies show that lung recruitment can improve patients' clinical outcomes, such as reducing mortality in patients with ARDS and shortening hospitalization time, but another part of the studies indicate that lung recruitment can not improve the prognosis of patients with ARDS $[9,10,22]$. The reasons of contradictory results may be related to a variety of factors such as the different ARDS causes, severity, ventilation strategies, respirator parameter setting and the lung RMs in different studies [3,22]. Therefore, the reaction of different patients with ARDS shows high heterogeneity to lung recruitment, a certain kind of lung RM may benefit some patients, but cause excessive alveolar expansion in another part of patients and aggravate the ARDS, thus counteract the possible benefits from lung recruitment [23].

In addition, with the increasing understanding of pathophysiological mechanisms of ARDS, the researchers have found that different types of ARDS patients have different response to mechanical ventilation and drug intervention. At present, one universal classification is to divide the ARDS into pulmonary ARDS and extrapulmonary ARDS [24]. The main pathological mechanism of pulmonary ARDS is primary alveolar damage; and the main mechanism of extrapulmonary ARDS is the pulmonary capillary endothelial injury caused by extrapulmonary factors $[25,26]$. However, a series of studies based the classification system failed to achieve consistent conclusion in radiological manifestations, the degree of lung inflammation, reactivity to respiratory therapy, in-hospital mortality, and so on in the two subtypes of ARDS patients [27,28]. Most scholars believe that the response of extrapulmonary ARDS to lung recruitment is much better than pulmonary ARDS [29,30], and a multi-center study in 2007 shows that the pulmonary ARDS and extrapulmonary ARDS reactivity to lung recruitment are similar [31]. In this study, it was found that the inducing factors of ARDS in some patients include both pulmonary factors and extrapulmonary factors, so it is difficult to further define what subtype of ARDS patients can benefit more from lung recruitment strategy.

Although it is found in this study that the lung recruitment strategy cannot improve clinical outcomes in patients with ARDS, it is found that the lung recruitment can improve the oxygenation in patients with ARDS. $\mathrm{PaO}_{2}$ of lung recruitment group rises gradually from $\mathrm{D} 1$ to $\mathrm{D} 7$ when compared with $\mathrm{PaO}_{2}$ of non-lung recruitment group. And as far as the $\mathrm{PaO}_{2} / \mathrm{FiO}_{2}$ is concerned, this trend is more obvious, and the $\mathrm{PaO}_{2} / \mathrm{FiO}_{2}$ of lung recruitment group on D7 is significantly higher than that of non-lung recruitment group. This is because that in order to prevent the oxygen toxicity and pulmonary atelectasis caused by continuous high-concentration of oxygen inspiration, $\mathrm{FiO}_{2}$ is prompt to be reduced if enough oxygenation can be maintained. Thus, the improvement of oxygenation is not necessarily embodied in the rise of $\mathrm{PaO}_{2}$, and may also be in the reduction of $\mathrm{FiO}_{2}$. Therefore, $\mathrm{PaO}_{2} / \mathrm{FiO}_{2}$ can more comprehensively reflect the oxygenation improvement during mechanical ventilation in patients with ARDS. A similar situation is also reported in abroad study, high PEEP, persistent lung expansion, CPAP and other lung recruitment strategies can all improve the patient's $\mathrm{PaO}_{2}$ and improve oxygenation, and this effect is most apparent within $30 \mathrm{~min}-2 \mathrm{~h}$ after lung recruitment, and then gradually falls back to the levels before recruitment $[8,10,32-33]$.

Lung recruitment not only influences the patient's oxygenation, but also has certain influence on the patients' hemodynamics. The study of Lim and others shows that implementation of lung RM can lead to real-time drop of cardiac output and mean arterial pressure, but they can return to normal after 5-15 min [34]. As the immediate effect of the lung recruitment influence on hemodynamics has been explored in foreign articles, our research focused on whether the lung recruitment has continuous influence on hemodynamics, and the results showed that $2 \mathrm{~h}$ after the lung RM in lung recruitment group, the hemodynamic indices were not significantly different from those of non-lung recruitment group, which indicates that the lung recruitment influence on the hemodynamics is temporary. This temporary hemodynamic change may be related to the returned blood volume decrease caused by transient intrathoracic pressure increase during lung recruitment.

To sum up, protective lung ventilation strategy combined with lung $\mathrm{RM}$ can improve the indicators such as $\mathrm{PaO}_{2}, \mathrm{FiO}_{2}$ and $\mathrm{PaO}_{2} /$ $\mathrm{FiO}_{2}$ on D7, but failed to improve the final outcomes such as 28-day mortality, ICU mortality and in-hospital mortality.

\section{Conflict of interest statement}

We declare that we have no conflict of interest. 


\section{Acknowledgement}

This work was funded by the Effect and Mechanism of Nrf2/ARE Pathway in Hydrogen Treatment of Seawater Drowning-induced Acute Lung Injury (No: 2016QN19).

\section{References}

[1] Matthay MA, Zemans RL. The acute respiratory distress syndrome: pathogenesis and treatment. Annu Rev Pathol 2011; 6: 147-163.

[2] Briel M, Meade M, Mercat A, Brower RG, Talmor D, Walter SD, et al. Higher vs lower positive end-expiratory pressure in patients with acute lung injury and acute respiratory distress syndrome: systematic review and meta-analysis. JAMA 2010; 303(9): 865-873.

[3] Ochiai R. Mechanical ventilation of acute respiratory distress syndrome. J Intensive Care 2015; 3(1): 25.

[4] Malhotra A. Low-tidal-volume ventilation in the acute respiratory distress syndrome. $N$ Engl J Med 2007; 357(11): 1113-1120.

[5] Matthay MA, Ware LB, Zimmerman GA. The acute respiratory distress syndrome. J Clin Invest 2012; 122(8): 2731-2740.

[6] Santiago VR, Rzezinski AF, Nardelli LM, Silva JD, Garcia CS, MaronGutierrez T, et al. Recruitment maneuver in experimental acute lung injury: the role of alveolar collapse and edema. Crit Care Med 2010; 38(11): 2207-2214

[7] Sousse LE, Herndon DN, Andersen CR, Ali A, Benjamin NC, Granchi $\mathrm{T}$, et al. High tidal volume decreases adult respiratory distress syndrome, atelectasis, and ventilator days compared with low tidal volume in pediatric burned patients with inhalation injury. J Am Coll Surg 2015; 220(4): 570-578.

[8] Riva DR, Oliveira MB, Rzezinski AF, Rangel G, Capelozzi VL, Zin WA, et al. Recruitment maneuver in pulmonary and extrapulmonary experimental acute lung injury. Crit Care Med 2008; 36(6): 1900-1908.

[9] Hodgson C, Keating JL, Holland AE, Davies AR, Smirneos L, Bradley $\mathrm{SJ}$, et al. Recruitment manoeuvres for adults with acute lung injury receiving mechanical ventilation. Cochrane Database Syst Rev 2009; (2): CD006667.

[10]Fan E, Wilcox ME, Brower RG, Stewart TE, Mehta S, Lapinsky SE, et al. Recruitment maneuvers for acute lung injury: a systematic review. $A m$ J Respir Crit Care Med 2008; 178(11): 1156-1163.

[11]Xi XM, Jiang L, Zhu B; RM group. Clinical efficacy and safety of recruitment maneuver in patients with acute respiratory distress syndrome using low tidal volume ventilation: a multicenter randomized controlled clinical trial. Chin Med J (Engl) 2010; 123(21): 3100-3105.

[12]Brower RG, Matthay MA, Morris A, Schoenfeld D, Thompson BT, Wheeler A. Ventilation with lower tidal volumes as compared with traditional tidal volumes for acute lung injury and the acute respiratory distress syndrome. N Engl J Med 342(18): 1301-1308.

[13]Lim CM, Jung H, Koh Y, Lee JS, Shim TS, Lee SD, et al. Effect of alveolar recruitment maneuver in early acute respiratory distress syndrome according to antiderecruitment strategy, etiological category of diffuse lung injury, and body position of the patient. Crit Care Med 2003; 31(2): 411-418.

[14]Bellani G, Laffey JG, Pham T, Fan E, Brochard L, Esteban A, et al. Epidemiology, patterns of care, and mortality for patients with acute respiratory distress syndrome in intensive care units in 50 countries. JAMA 2016; 315(8): 788-800

[15]Grasso S, Mascia L, Del Turco M, Malacarne P, Giunta F, Brochard L, et al. Effects of recruiting maneuvers in patients with acute respiratory distress syndrome ventilated with protective ventilatory strategy. Anesthesiology 2002; 96(4): 795-802.

[16]Valente Barbas CS. Lung recruitment maneuvers in acute respiratory distress syndrome and facilitating resolution. Crit Care Med 2003; 31(4
Suppl): S265-271.

[17]Villagrá A, Ochagavía A, Vatua S, Murias G, Del Mar Fernández M, Lopez Aguilar J, et al. Recruitment maneuvers during lung protective ventilation in acute respiratory distress syndrome. Am J Respir Crit Care Med 2002; 165(2): 165-170.

[18]Morán I, Blanch L, Fernández R, Fernández-Mondéjar E, Zavala E, Mancebo J. Acute physiologic effects of a stepwise recruitment maneuver in acute respiratory distress syndrome. Minerva Anestesiol 2011; 77(12): 1167-1175.

[19]Brower RG, Morris A, MacIntyre N, Matthay MA, Hayden D, Thompson $\mathrm{T}$, et al. Effects of recruitment maneuvers in patients with acute lung injury and acute respiratory distress syndrome ventilated with high positive end-expiratory pressure. Crit Care Med 2003; 31(11): 2592-2597.

[20]Hinz J, Moerer O, Quintel M. Recruitment maneuvers for patients with lung failure. When, how, whether or not? Anaesthesist 2005; 54(11): 1111-1119.

[21]Lachmann B. Open up the lung and keep the lung open. Intensive Care Med 1992; 18(6): 319-321.

[22]Suzumura EA, Figueiró M, Normilio-Silva K, Laranjeira L, Oliveira $\mathrm{C}$, Buehler AM, et al. Effects of alveolar recruitment maneuvers on clinical outcomes in patients with acute respiratory distress syndrome: a systematic review and meta-analysis. Intensive Care Med 2014; 40(9): 1227-1240.

[23]Lu Q. How to assess positive end-expiratory pressure-induced alveolar recruitment? Minerva Anestesiol 2013; 79(1): 83-91.

[24]Santos CL, Moraes L, Santos RS, dos Santos Samary C, Silva JD, Morales MM, et al. The biological effects of higher and lower positive end-expiratory pressure in pulmonary and extrapulmonary acute lung injury with intra-abdominal hypertension. Crit Care 2014; 18(3): R121.

[25]Pelosi P, D’Onofrio D, Chiumello D, Paolo S, Chiara G, Capelozzi VL, et al. Pulmonary and extrapulmonary acute respiratory distress syndrome are different. Eur Respir J Suppl 2003; 42: 48s-56s.

[26]Sehgal IS, Dhooria S, Behera D, Agarwal R. Acute respiratory distress syndrome: Pulmonary and extrapulmonary not so similar. Indian J Crit Care Med 2016; 20(3): 194-197.

[27]Morisawa K, Fujitani S, Taira Y, Kushimoto S, Kitazawa Y, Okuchi K, et al. Difference in pulmonary permeability between indirect and direct acute respiratory distress syndrome assessed by the transpulmonary thermodilution technique: a prospective, observational, multi-institutional study. J Intensive Care 2014; 2(1): 24.

[28]Agarwal R, Srinivas R, Nath A, Jindal SK. Is the mortality higher in the pulmonary vs the extrapulmonary ARDS? A meta analysis. Chest 2008; 133(6): 1463-1473.

[29]Pelosi P, Caironi P, Gattinoni L. Pulmonary and extrapulmonary forms of acute respiratory distress syndrome. Semin Respir Crit Care Med 2001; 22(3): 259-268.

[30]Riva DR, Oliveira MB, Rzezinski AF, Rangel G, Capelozzi VL, Zin WA, et al. Recruitment maneuver in pulmonary and extrapulmonary experimental acute lung injury. Crit Care Med 2008; 36(6): 1900-1908.

[31]Thille AW, Richard JC, Maggiore SM, Ranieri VM, Brochard L. Alveolar recruitment in pulmonary and extrapulmonary acute respiratory distress syndrome: comparison using pressure-volume curve or static compliance. Anesthesiology 2007; 106(2): 212-217.

[32]Oczenski W, Hörmann C, Keller C, Lorenzl N, Kepka A, Schwarz S, et al. Recruitment maneuvers after a positive end-expiratory pressure trial do not induce sustained effects in early adult respiratory distress syndrome. Anesthesiology 2004; 101(3): 620-625.

[33]Dyhr T, Bonde J, Larsson A. Lung recruitment manoeuvres are effective in regaining lung volume and oxygenation after open endotracheal suctioning in acute respiratory distress syndrome. Crit Care 2003; 7(1): 55-62.

[34]Lim SC, Adams AB, Simonson DA, Dries DJ, Broccard AF, Hotchkiss $\mathrm{JR}$, et al. Intercomparison of recruitment maneuver efficacy in three models of acute lung injury. Crit Care Med 2004; 32(12): 2371-2377. 